\title{
DESIGN PROCESS, DRAWINGS ARE RE-PRESENTATIONS OF IDEAS
}

col Fay

In terms of a design practice, fashion is often judged on the final resolution, an approach which diminishes the very robust and critical stages of process that inform the final outcome and cloaks the design resolution in the somewhat enigmatic posture of the creative genius. However, working with others and publishing in both fashion and architecture has shown that this approach is not universal, nor is it accepted as a finite and therefore concrete pathway in itself. Unveiling the process by allowing us entry into it through visual re-presentation goes someway to demystifying this creative practice and allows the breath of knowledge involved, both conceptual and tactile, to be acknowledged.

The Renaissance practise of disegno, a technique bringing together artwork and craftwork, acknowledges the importance of process in giving meaning to the act of 'making' or production. Originally applied to the arts of sculpture, painting and architecture, this practise suggests that to realise the potential of something before it is concrete is a necessary step in the articulation of making (Hartoonian, 2014). The concept of process proposed here suggests an authentic method of extracting meaning from a creative endeavour through capturing ideas through visual manifestations, namely drawing.

However, expanding the idea of "drawing" to include three-dimensional processes acknowledges the multiplexity of representational practices in a contemporary sense. "Drawing" can be considered as a process of imagining, seeing and representing ideas about the "ex-perience" - a connecting practice, a re-presentation. For Peter Downton (2004), sketch drawing or graphic representations executed on paper are no different from the act of drawing with paper. He therefore describes the surface of inscription as arbitrary, as within the creative process the intention is to make conscious thought tangible. Legitimacy therefore lies in the formalisation of the creative process, allowing it to be captured, critiqued and made visible; it suggests that within the process of making is a process of becoming.

For me, process is the major critical element within the development of any creative design project, as it allows for a rigorous interrogation of thought, trial and evaluation to occur simultaneously. For me, the qualities of making lie not in the intention to produce an object; rather, they are concentrated in the process of thinking that allows the form to materialise as an embodiment of an idea. The final realisation I term "residue" - a trace of the research. It is the manifestation of processed thoughts, suggestions and conversations, both with myself and with the work of others - elements that come together not finished, but rather are allowed to be fragmentary. Downton refers to process as "the immediate stages" of creation, which as critical parts will take their place in the whole when finalised. He speaks therefore of agency within the design process, the intention of making through creative exploration.

Nigel Cross (2006, pp. 34-38) refers to this type of practice as a "critical, reflective dialogue" that enables us to review our research as abstract ideas capable of interrogation and able to be manipulated, rather than as elements on their way to becoming refined solutions. For Cross, the design process - which I have interpreted as 2D and $3 \mathrm{D}$ explorations - is necessary in order for the design itself to undergo a critique that is both micro and macro simultaneously, a selective ordering of what is relevant. As a method it allows the design solution, played out through multiple explorations, to be a proposition rather than a resolution. 
Process-driven practices, as represented in Hywel Davis's books (20I0, 20I3), go some way to making the process of fashion designers visible - and set a model for interrogating fashion beyond its final resolution. In this new section of the Fashion special issue of Scope: Art and Design, Special Issue Fashion Forward >> Disruption, we are offered insights into how varied and conscious the design phase of fashion can be, which opens up the discourse beyond a three-dimensional objective. These dialogues offer us a breadth of exploration into what fashion is, what fashion could be, and the things it must be conscious of - all suggesting that fashion is beyond formal classification and should be allowed an opportunity to expand its perceived boundaries. Collectively, these contributions represent a body of knowledge that is placed alongside the work of others in order to establish a connection to the everexpanding field of fashion and its opening up to the multi-disciplinarity of practices.

What Davis's books and the exemplars presented here suggest is that they are not illustrations of a predesign process, but rather a different kind of practise; not finished work, but fragments that are captured. This reminds us that it is not necessarily the point of arrival, but rather the journey, that is the practise itself.

col Fay is a modernist, with a preference for form and structure over decoration. She holds a MFA, and has a longstanding interest in those aspects of design that involve the body, jewellery, exhibitions, fashion and architecture. Her understanding of the importance of process and the role in which artifacts aid design development provides a unique and strong viewpoint for this introduction.

\section{DOI links to the designers on the following pages:}

\begin{tabular}{|c|c|}
\hline Margo Barton & https://doi.org/ | 0.34074/scop. 1021009 \\
\hline Stella Lange & https://doi.org/ | 0.34074/scop. 1021008 \\
\hline Simon Swale & https://doi.org/| 0.34074/scop. 102 | \\
\hline Anessa Starker & tps://doi.org// 0.34074/scop. 102 \\
\hline
\end{tabular}

\section{REFERENCES}

Cross, N. (2006). Designerly ways of knowing. Springer.

Davis, H. (2010). Fashion Designers' Sketchbooks. Laurence King Publishing

Davis, H. (20।3). Fashion Designers' Sketchbooks Two. Laurence King Publishing

Downton, P. (2004). Studies in design research: Ten epistemological pavilions. RMIT University Press.

Hartoonian, G. (2014). Bernard Tschumi draws architecture! Footprint: Delft Architecture Theory Journal, 7, $29-44$. https://doi.org// 0.7480 